\title{
КОЛИЧЕСТВО НЕСЧАСТНЫХ СЛУЧАЕВ, ВЫЗВАННЫХ ЯДОВИТЫМИ ЖИВОТНЫМИ, С 2010 ПО 2014 ГОД В БРАЗИЛИИ
}

\section{ОРИГИНАЛЬНАЯ СТАТЬЯ}

SOEIRO, Selthon Macello Capiberibe ${ }^{1}$, FACCO, Lucas², FECURY, Amanda Alves ${ }^{3}$, ARAÚJO, Maria Helena Mendonça de ${ }^{4}$, OLIVEIRA, Euzébio de ${ }^{5}$, DENDASCK, Carla Viana $^{6}$, SOUZA, Keulle Oliveira da ${ }^{7}$, DIAS, Claudio Alberto Gellis de Mattos ${ }^{8}$

SOEIRO, Selthon Macello Capiberibe. Et al. Количество несчастных случаев, вызванных ядовитыми животными, с 2010 по 2014 год в Бразилии. Revista Científica Multidisciplinar Núcleo do Conhecimento. 05-й год, Эд. 12, Vol. 01, стр. 05-17. Декабрь 2020 года. ISSN: 2448-0959, Ссылка доступа: https://www.nucleodoconhecimento.com.br/здравоохранение/количествонесчастных, DOI: 10.32749/nucleodoconhecimento.com.br/ru/67473

\section{PE3ЮME}

Ядовитые животные являются те, которые имеют механизм для инъекций яда. Различные яды или яды могут вызвать боль, разрыв кровеносных сосудов, ожог, волдыри, отеки, некротические травмы, кровоизлияние, рвота крови,

\footnotetext{
${ }^{1}$ Выпускной в области компьютерных наук.

${ }^{2}$ Студент медицинского курса Федерального университета Amapá (UNIFAP).

${ }^{3}$ Биомедицинская, кандидат биологических наук в области тропических болезней, профессор и исследователь медицинского курса Федерального университета Amapá (UNIFAP).

${ }^{4}$ Врач, профессор и исследователь медицинского курса Федерального университета Amapá (UNIFAP).

${ }^{5}$ Биолог, кандидат медицинских наук по актуальным заболеваниям, профессор и исследователь курса физкультуры Федерального университета Pará (UFPA).

${ }^{6}$ Богослов, кандидат психологических наук, исследователь Центра исследований и перспективных исследований - СЕРА.

7 Социолог, студент магистратуры по антропогенным исследованиям в Амазонии, член исследовательской группы «Лаборатория образования, окружающей среды и здоровья» (LEMAS/UFPA). ${ }^{8}$ Биолог, кандидат теоретических и летных исследований, профессор и исследователь Высшей программы профессионального и технологического образования (PROFEPT), Федеральный институт Amapá (IFAP).
}

RC: 67473

Доступно в:

https://www.nucleodoconhecimento.com.br/здравоохранение/количество- 
наличие крови в моче, кровотечение в носу, интенсивное потоотделение, низкое кровяное давление, переохлаждение и неврологические проблемы. Целью данной статьи является показать количество несчастных случаев, вызванных ядовитыми животными в период с 2010 по 2014 год в Бразилии. Рассматривается как забытые причины заболеваний, несчастные случаи, вызванные ядовитыми животными требуют большего внимания общественного здравоохранения. Пауки, скорпионы и змеи являются основными причинами этих несчастных случаев. Среди детей больше всего страдают мальчики, и одной из основных причин этой проблемы является отсутствие надзора в повседневной деятельности. Производство сыворотки для лечения несчастных случаев с одидизами в Бразилии усиливается, и объем производимой продукции способен покрыть общее число случаев заболевания в стране. Вместе с тем существует проблема, связанная с распространением этой сыворотки, поскольку районы коренного населения и районы отдаленных населенных пунктов не имеют достаточной доступности, что позволяет иметь негативные последствия для отдельных лиц, что повышает вероятность смерти от такого рода несчастных случаев.

Ключевые слова: Эпидемиология, яд, яд.

\section{ВВЕДЕНИЕ}

Ядовитыми животными являются те, которые имеют механизм для инъекций яда, который может быть жало, жало или зубы (Pinho и Pardal, 2015). Некоторые виды пчел, змей, ос, маримбондо, пауков, скорпионов и гусениц могут рассматриваться как ядовитые животные (BREDT и LITCHTENEKER, 2014; NEIVA, et al., 2019).

Различные яды или яды могут вызвать боль, разрыв кровеносных сосудов, ожог, волдыри, отеки, некротические травмы, кровоизлияние, рвота крови,

RC: 67473

Доступно в:

https://www.nucleodoconhecimento.com.br/здравоохранение/количество- 
наличие крови в моче, кровотечение в носу, сильное потоотделение, низкое кровяное давление, переохлаждение и неврологические проблемы (LIMA et al., 2017; NEIVA, et al., 2019).

Лечение несчастных случаев с ядовитыми животными производится, в большинстве случаев, с помощью антиядомной сыворотки, которая содержит специфические антитела для борьбы с токсинами каждого животного, и это должно быть применено как можно скорее, чтобы избежать обострения дела (SOUZA и MACHADO, 2017).

Для предотвращения несчастных случаев со змеями, перчатки и сапоги следует использовать при уборке кустов, мусора, сухих листьев, мусора и других, так как такие животные предпочитают жаркие и влажные места. Вы не должны положить руки в отверстия, вы должны избегать распространения крыс, так как это змеиная пища и, кроме того, необходимо, чтобы избежать накопления куста, дерева, кирпича и других материалов, которые могут стать убежищем для животных, которые служат в качестве пищи для змей (BRASIL, 2001).

Для предотвращения несчастных случаев с паукообразными, пустырями, садами и дворами следует держаться под в стороне от щебня, кустарников, сухих листьев и строительных материалов, тем самым препятствуя их поиску укрытия. Кроме того, следует избегать растений с густой листвой возле стен; встряхнуть одежду и обувь перед ношением; носить перчатки и обувь при обращении и ходьбе в местах, которые могут содержать таких животных; отверстия уплотнения где паукообразные могут пересечь (главным образом на ноче, из-за их привычек); положить экраны в стоки, раковины и танки; предотвращение распространения насекомых, которые являются пищей паукообразных (одна из мер заключается в том, чтобы держать бытовые отходы в помещении, чтобы избежать тараканов и мух); снять кровати со стен и не дать мушкетерам и простыням прикоснуться к полу; избегать убийства

RC: 67473

Доступно в:

https://www.nucleodoconhecimento.com.br/здравоохранение/количество- 
паукообразных хищников (лягушки, птицы, ящерицы, куры, гуси, обезьяны и другие) (BRASIL, 2001).

Число случаев заболевания в Бразилии в период с 1986 по 2016 год составило 2183 989. Число случаев заболевания в регионе Бразилии в период с 1986 по 2016 год: Северный регион: 233 586; Северо-восточный регион: 624 615; юговосточный регион: 758 238; южный регион: 427 442; Регион Среднего Запада: 140 108. Число случаев заболевания в Amapá в период с 1986 по 2016 год в Amapá 8463 (BRASIL, 2017).

\section{ЦЕЛИ}

Показать количество несчастных случаев, вызванных ядовитыми животными в период с 2010 по 2014 год в Бразилии.

\section{МЕТОД}

Исследование проводилось в базе данных DATASUS (http://datasus.saude.gov.br/). Национальные данные были собраны в соответствии со следующими этапами: А) Мы открыли ссылку datasus.saude.gov.br, переместили стрелку с помощью мыши на вкладку «Доступ к информации», а затем перешли на вкладку «Информация о здоровье (TABNET). ) », Щелкнул «Эпидемиологические и заболеваемость». На следующей странице нажмите «Зарегистрированные заболевания и расстройства - с 2007 г. и далее (SINAN)». На следующей странице мы выбрали «Несчастные случаи от ядовитых животных. В поле «Географический охват» был выбран вариант «Бразилия по регионам, штатам и муниципалитетам». С этого момента были выполнены следующие шаги: А) В строке был выбран «Год аварии»; в столбце «Неактивно» и в содержании «Уведомления». Все данные, собранные на этом и следующих этапах, относятся к периоду с 2010 по 2014

RC: 67473

Доступно в:

https://www.nucleodoconhecimento.com.br/здравоохранение/количество- 
год. В) В строке был выбран «Год аварии»; в столбце «Месяц аварии» и в содержании «Уведомления». В) В строке был выбран «Год аварии»; в столбце «Область уведомления» и в содержании «Уведомления». Г) В строке был выбран «Год аварии»; в столбце «Возрастная группа» и в содержании «Уведомления». Е) В строке был выбран «Год аварии»; в столбце «Гонка» и в содержании «Уведомления». F) В строке был выбран «Год аварии»; в столбце «Секс» и в содержании «Уведомления». Ж) В строке был выбран «Год аварии»; в столбце «Беременная женщина» и в содержании «Уведомления». Н) В строке был выбран «Год аварии»; в столбце «Сокращение времени / услуга» и в содержании «Уведомления». I) В строке был выбран «Год аварии»; в столбце «Тип аварии» и в содержании «Уведомления». J) В строке был выбран «Год аварии»; в столбце «Оценить. Финал »и в содержании« Уведомления ». К) В строке был выбран «Год аварии»; в столбце «Развитие дела» и в содержании «Уведомления»

Данные были собраны в приложении Excel, компоненте пакета Microsoft Corporation Office. Библиографрическое исследование проводилось в научных статьях с использованием компьютеров из компьютерной лаборатории Федерального института образования, науки и техники Amapá, кампус Macapá, расположенной по адресу: Rodovia BR 210 KM 3, s/n - Bairro Brasil Novo. Почтовый индекс: 68.909-398, Macapá, Amapá, Бразилия.

\section{РЕЗУЛЬТАТЫ}

На рисунке 1 показано количество несчастных случаев, вызванных ядовитыми животными в период с 2010 по 2014 год, что свидетельствует о росте с каждым годом.

RC: 67473

Доступно в:

https://www.nucleodoconhecimento.com.br/здравоохранение/количество- 
На рисунке 1 показано количество случаев несчастных случаев, вызванных ядовитыми животными в Бразилии в период с 2010 по 2014 год.

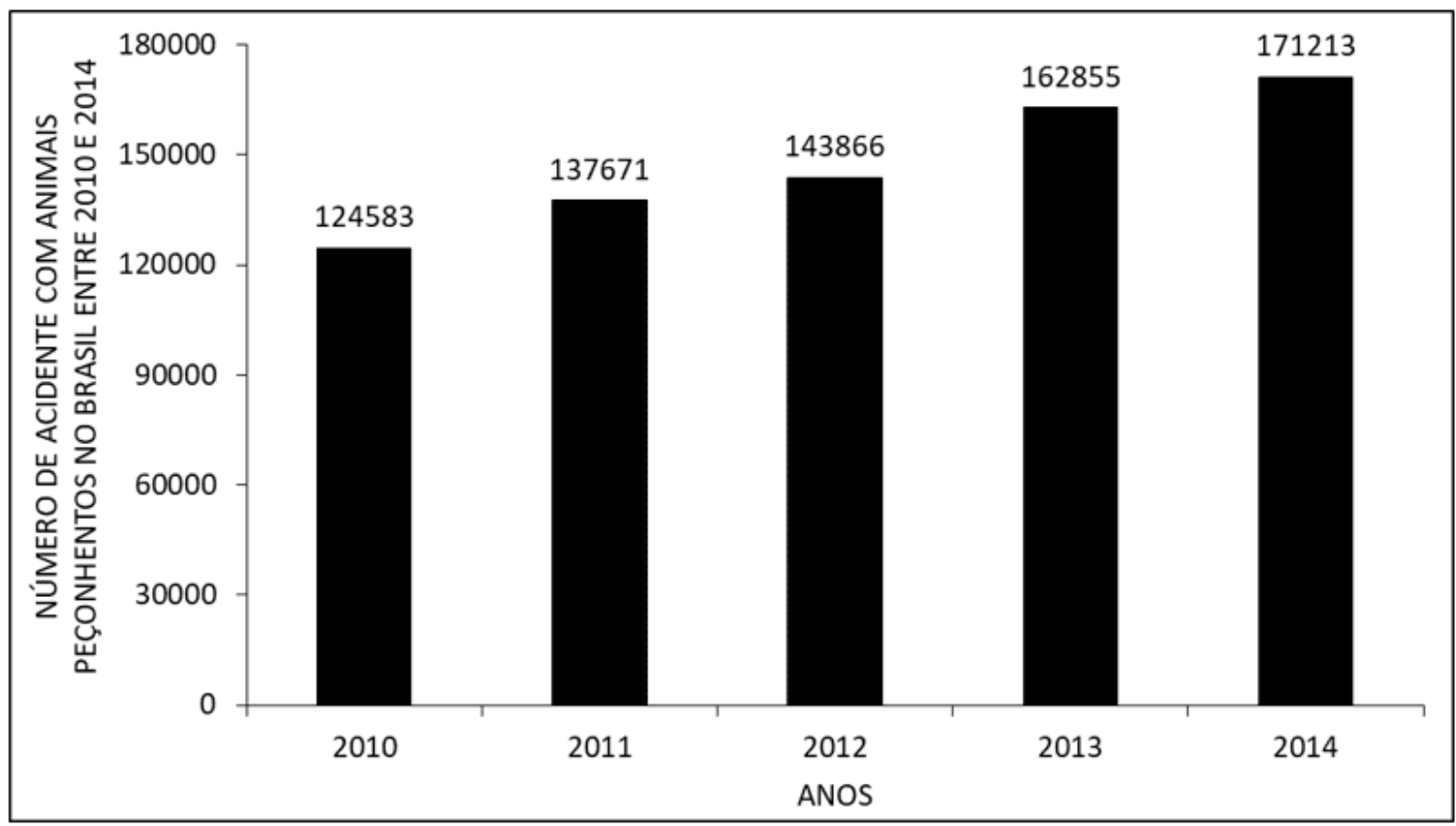

На рисунке 2 показано количество несчастных случаев, вызванных ядовитыми животными в месяц в период с 2010 по 2014 год. Наибольшее число происходит в январе, показывая падение в фреврале, увеличиваясь снова в марте и снова снижается до июля. Это месяц с наименьшим числом случаев заболевания, с увеличением в последующие месяцы.

RC: 67473

Доступно в:

https://www.nucleodoconhecimento.com.br/здравоохранение/количество- 
На рисунке 2 показано количество случаев несчастных случаев, вызванных ядовитыми животными в Бразилии в период с 2010 по 2014 год, в течение нескольких месяцев в году.

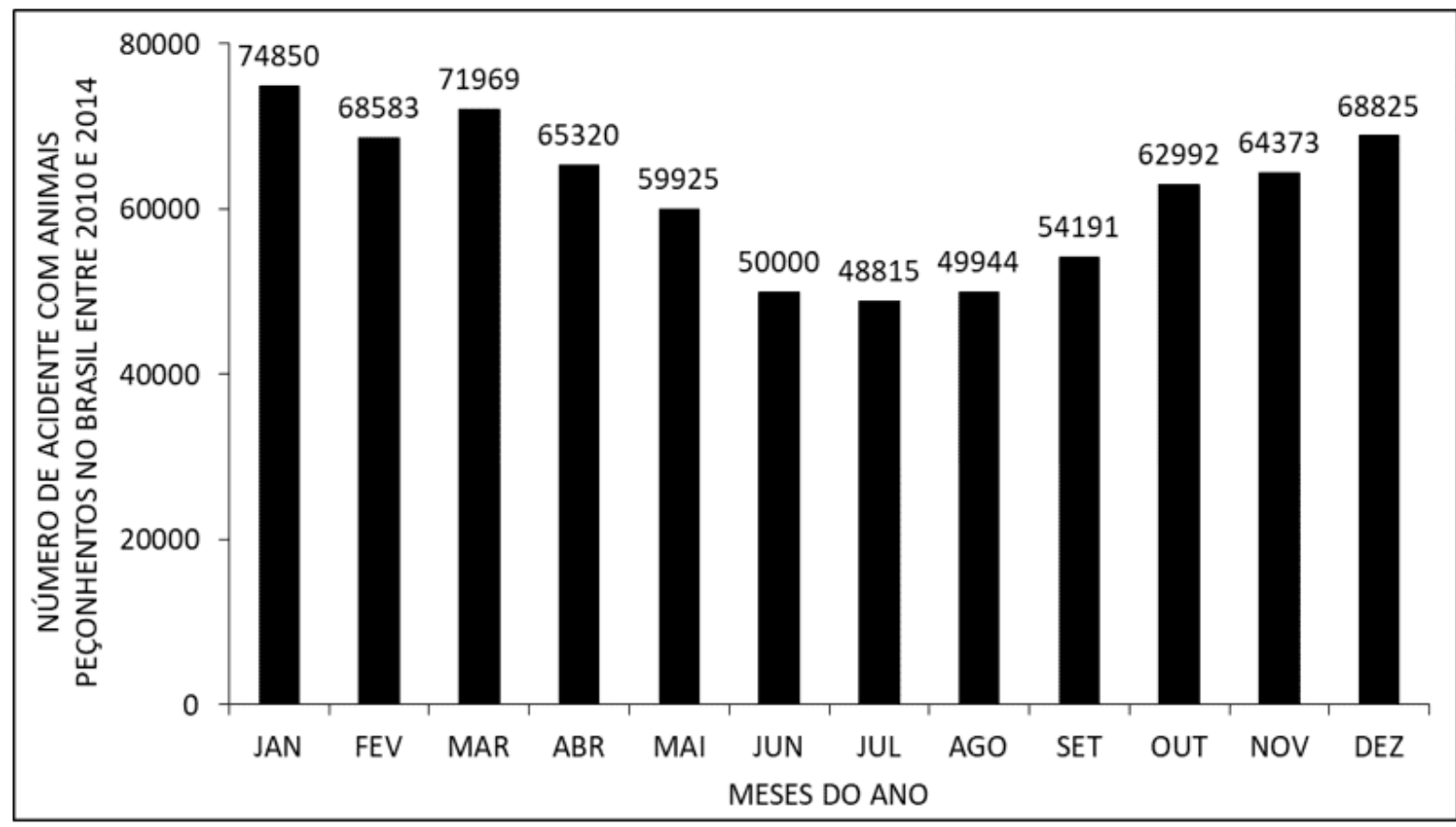

На рисунке 3 показано количество сообщений о несчастных случаях, вызванных ядовитыми животными в Бразилии в период с 2010 по 2014 год, в регионах страны. Наибольшее число случаев заболевания происходит в юго-восточном регионе, за которым следуют, соответственно, северо-восточные, южные, северные и средние регионы.

RC: 67473

Доступно в:

https://www.nucleodoconhecimento.com.br/здравоохранение/количество- 
На рисунке 3 показано число случаев несчастных случаев, вызванных ядовитыми животными в Бразилии в период с 2010 по 2014 год, в регионах страны.

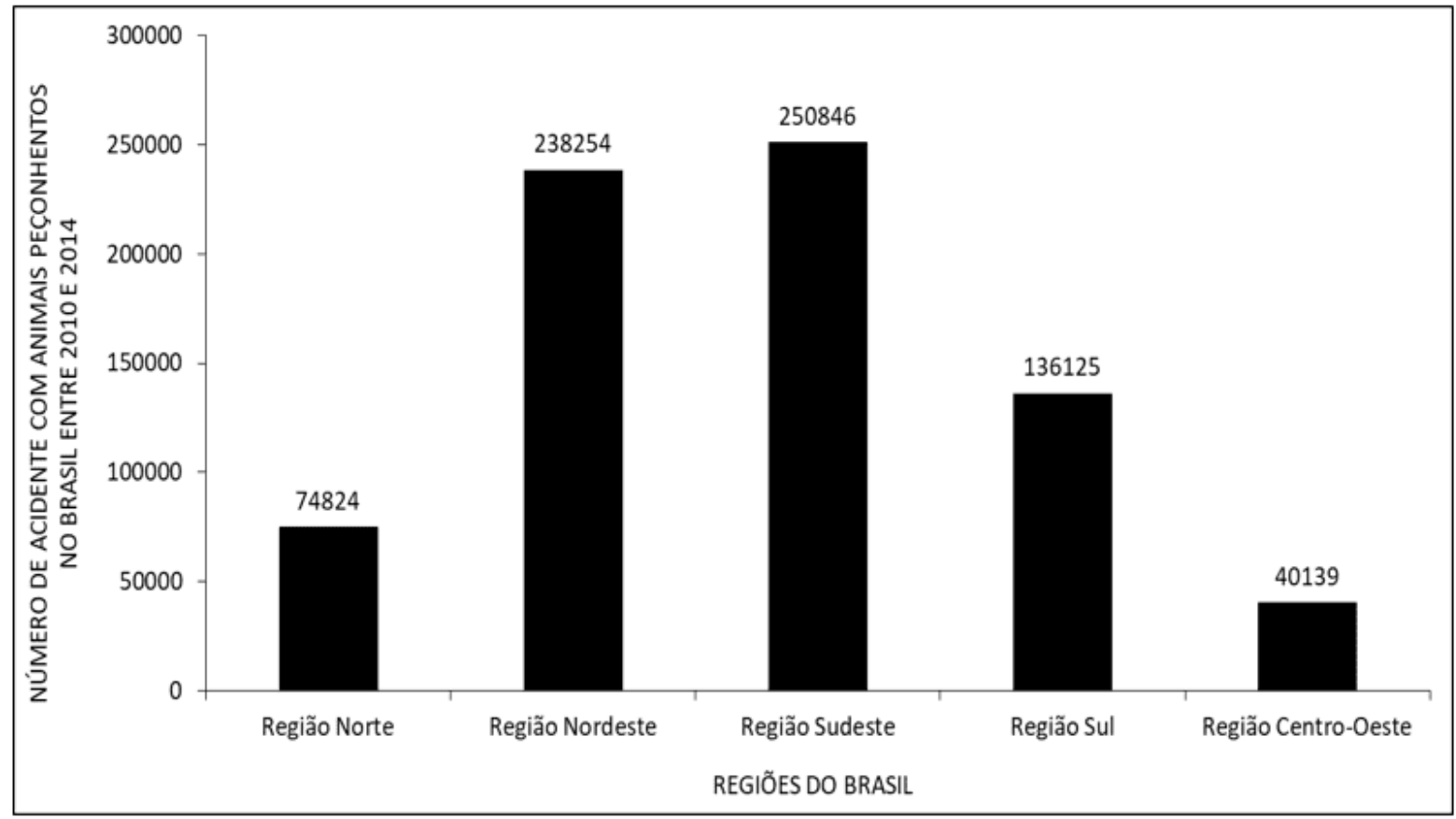

На рисунке 4 показано количество сообщений о несчастных случаях, вызванных ядовитыми животными в Бразилии в период с 2010 по 2014 год, по признаку пола. Наибольшее число случаев происходит с мужчинами.

RC: 67473

Доступно в:

https://www.nucleodoconhecimento.com.br/здравоохранение/количество- 
На рисунке 4 показано число случаев несчастных случаев, вызванных ядовитыми животными в Бразилии в период с 2010 по 2014 год, по признаку пола.

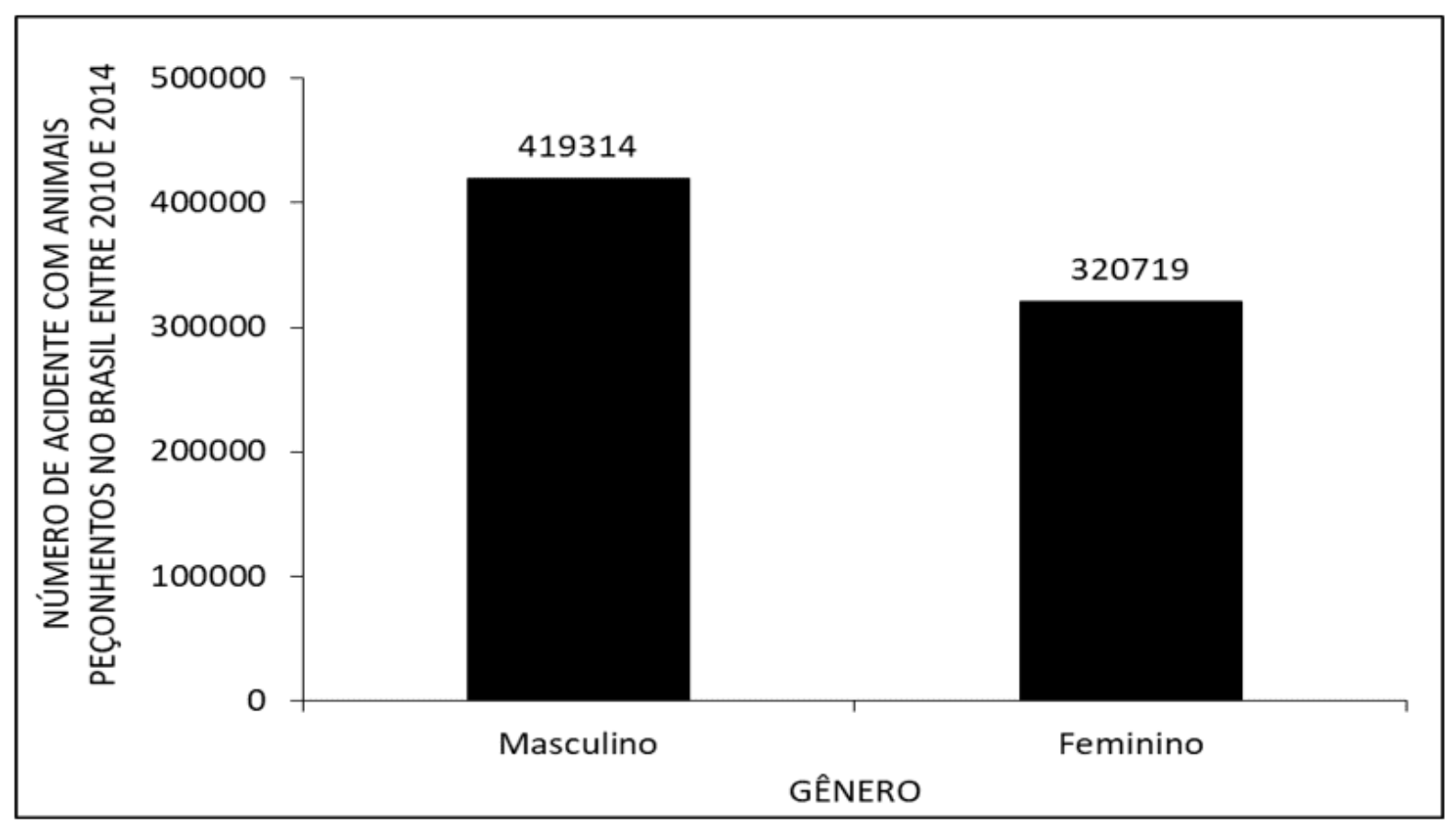

На рисунке 5 показано количество сообщений о несчастных случаях, вызванных ядовитыми животными в Бразилии в период с 2010 по 2014 год, по возрастным группам. Наибольшее количество случаев, по данным, происходит у людей в возрасте от 20 до 39 лет. Второе место по числу случаев заболевания появляются в группе в возрасте от 40 до 59 лет.

$\mathrm{RC}: 67473$

Доступно в:

https://www.nucleodoconhecimento.com.br/здравоохранение/количество- 
На рисунке 5 показано число случаев несчастных случаев, вызванных ядовитыми животными в Бразилии в период с 2010 по 2014 год, по возрастным группам.

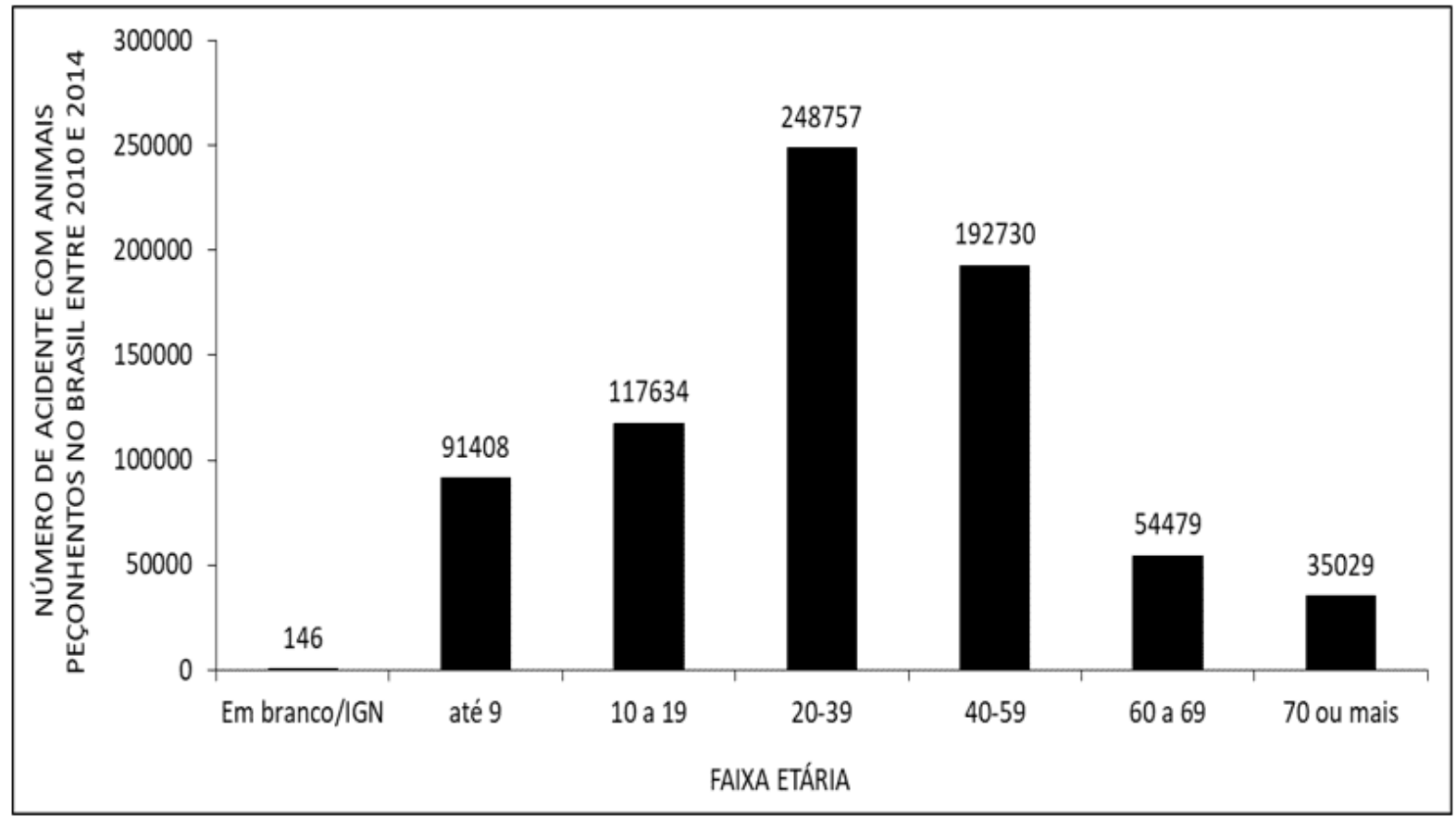

На рисунке 6 показано количество сообщений о несчастных случаях, вызванных ядовитыми животными в Бразилии в период с 2010 по 2014 год, по этническому признаку. Наибольшее число случаев происходит с людьми коричневого этнического происхождения, за которыми следуют люди, объявленные белыми и черными людьми, соответственно.

$\mathrm{RC}: 67473$

Доступно в:

https://www.nucleodoconhecimento.com.br/здравоохранение/количество- 
На рисунке 6 показано число случаев несчастных случаев, вызванных ядовитыми животными в Бразилии в период с 2010 по 2014 год, по этническому признаку.

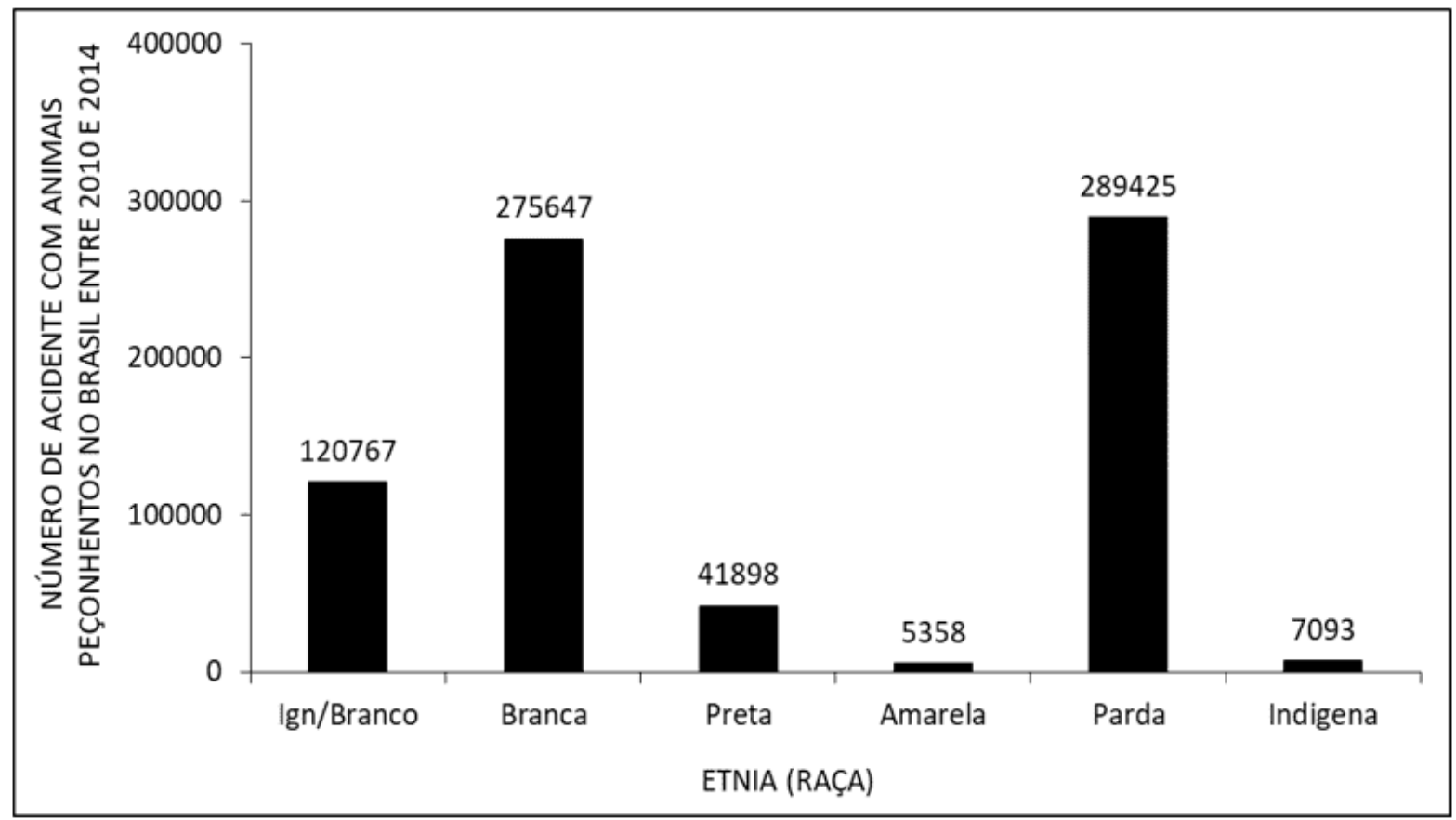

На рисунке 7 показано количество сообщений о несчастных случаях, вызванных ядовитыми животными в Бразилии в период с 2010 по 2014 год, по типу несчастного случая. Наибольшее число случаев произошло в авариях с участием скорпионов.

RC: 67473

Доступно в:

https://www.nucleodoconhecimento.com.br/здравоохранение/количество- 
На рисунке 7 показано число случаев несчастных случаев, вызванных ядовитыми животными в Бразилии в период с 2010 по 2014 год, по типу несчастных случаев.

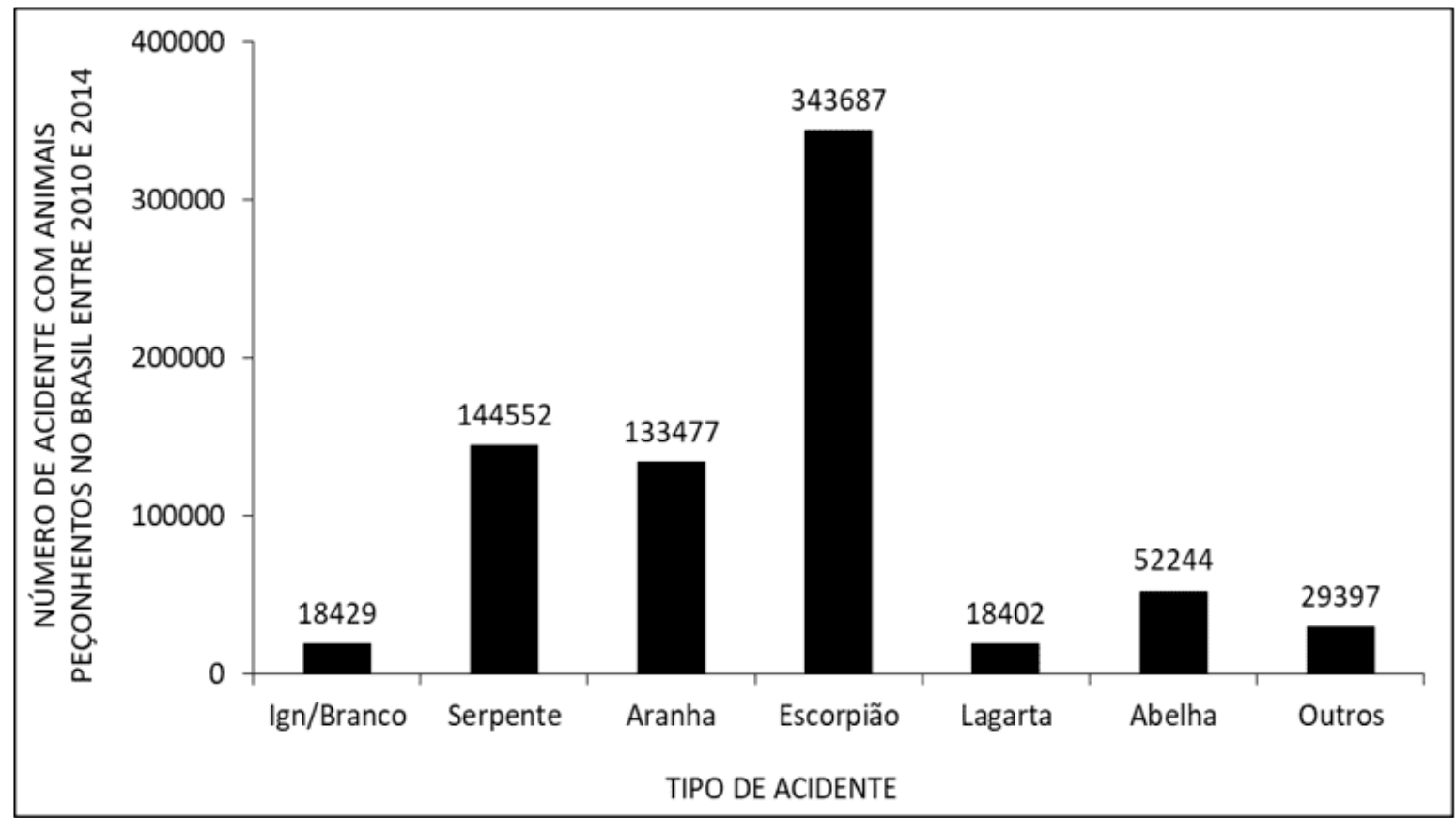

На рисунке 8 показано количество сообщений о несчастных случаях, вызванных ядовитыми животными в Бразилии в период с 2010 по 2014 год, в зависимости от стадий беременности. Наибольшее число случаев происходит с беременными женщинами во втором триместре беременности, за которыми следуют беременные женщины в первом и третьем триместрах, соответственно.

$\mathrm{RC}: 67473$

Доступно в:

https://www.nucleodoconhecimento.com.br/здравоохранение/количество- 
На рисунке 8 показано количество случаев несчастных случаев, вызванных ядовитыми животными в Бразилии в период с 2010 по 2014 год, в зависимости от стадий беременности.

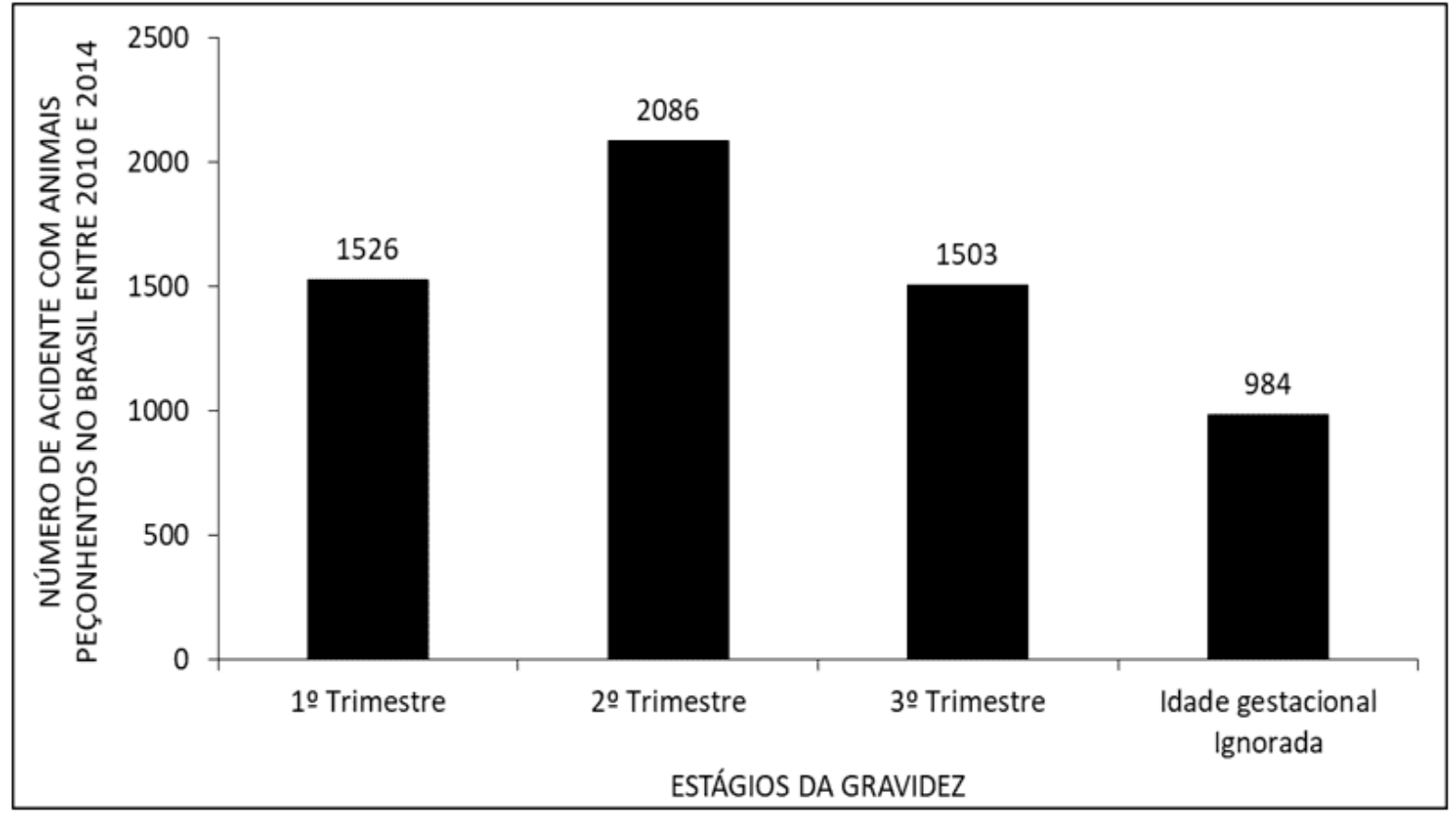

На рисунке 9 показано количество сообщений о несчастных случаях, вызванных ядовитыми животными в Бразилии в период с 2010 по 2014 год, в зависимости от времени, в течение нескольких часов между укусом и службы. Данные показывают, что наибольшее количество людей посещают от 0 до 3 часов после аварии.

RC: 67473

Доступно в:

https://www.nucleodoconhecimento.com.br/здравоохранение/количество- 
На рисунке 9 показано количество случаев несчастных случаев, вызванных ядовитыми животными в Бразилии в период с 2010 по 2014 год, в зависимости от времени в часах между укусом и уходом.

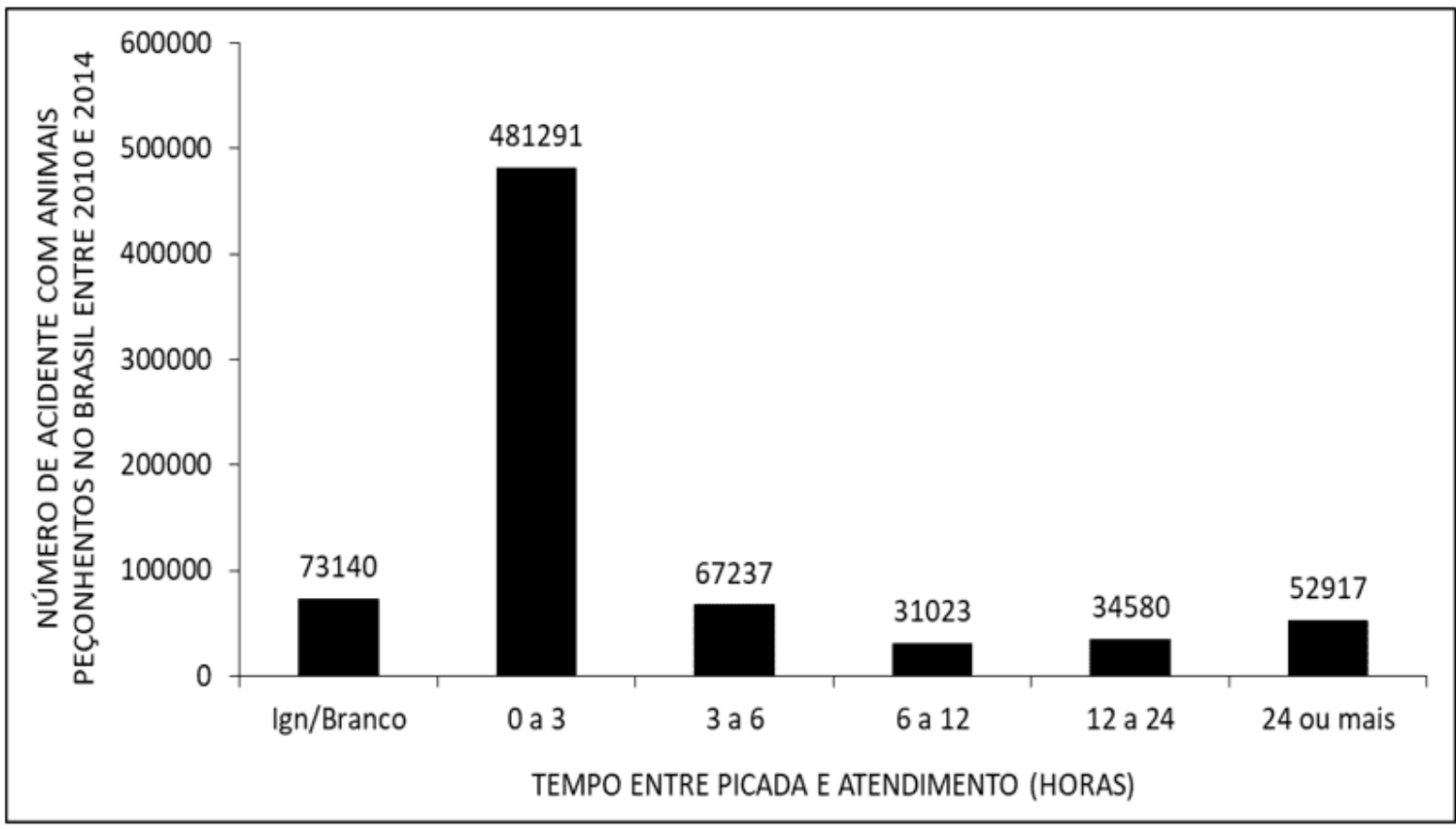

На рисунке 10 показано количество сообщений о несчастных случаях, вызванных ядовитыми животными в Бразилии в период с 2010 по 2014 год, по окончательной классификации аварии. Наибольшее число случаев заболевания было зарегистрировано в качестве окончательной классификации несчастного случая легкой степени.

RC: 67473

Доступно в:

https://www.nucleodoconhecimento.com.br/здравоохранение/количество- 
На рисунке 10 показано число случаев несчастных случаев, вызванных ядовитыми животными в Бразилии в период с 2010 по 2014 год, по окончательной классификации аварии.

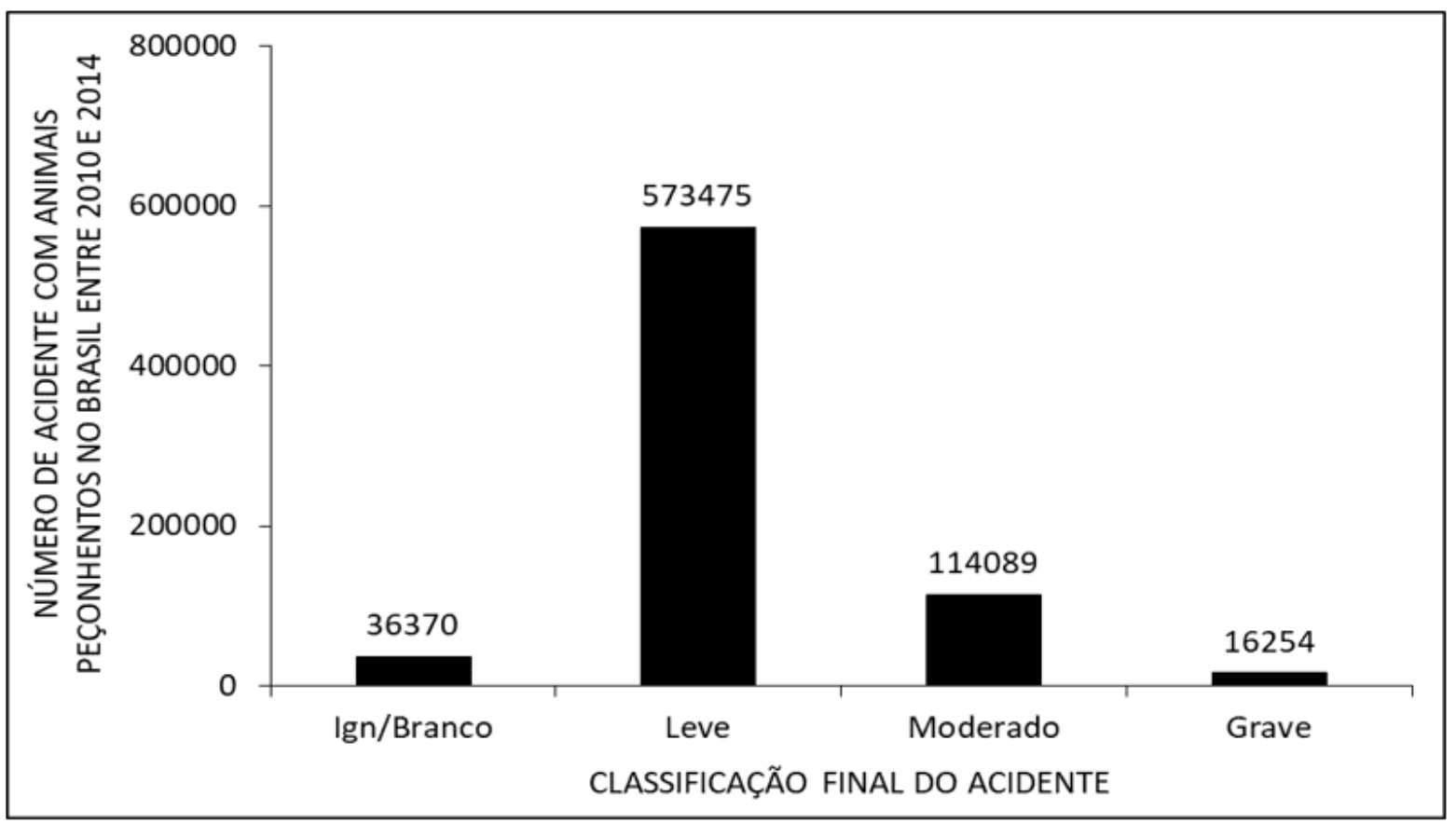

На рисунке 11 показано количество сообщений о несчастных случаях, вызванных ядовитыми животными в Бразилии в период с 2010 по 2014 год, в результате эволюции этого случая. Наибольшее число случаев заболевания было вылечено, при этом минимальное число случаев смерти.

RC: 67473

Доступно в:

https://www.nucleodoconhecimento.com.br/здравоохранение/количество- 
На рисунке 11 показано количество случаев несчастных случаев, вызванных ядовитыми животными в Бразилии в период с 2010 по 2014 год, в связи с развитием дела.

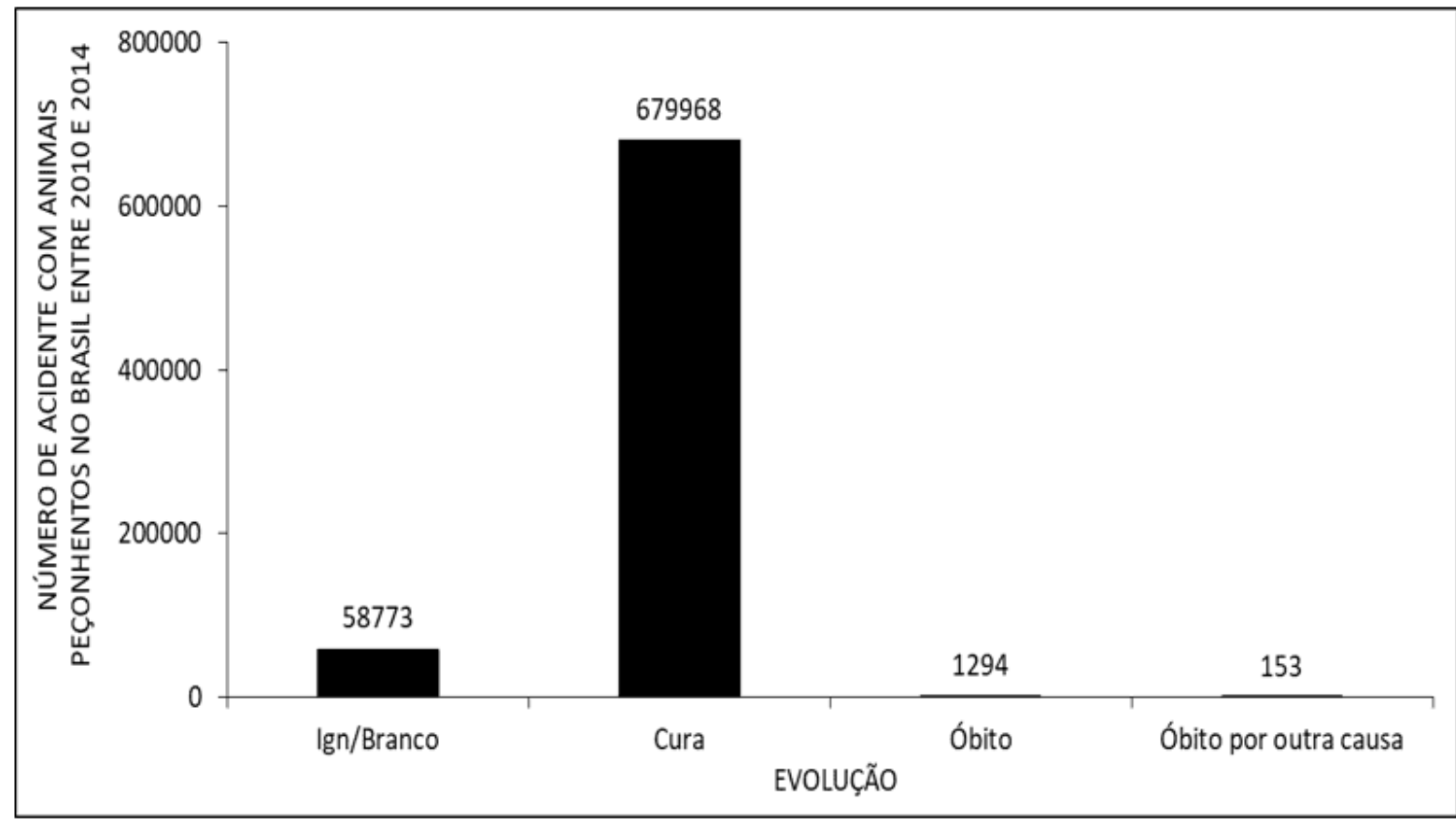

\section{ОБСУЖДЕНИЕ}

Несчастные случаи, вызванные ядовитыми животными, рассматриваются в качестве забытых причин болезней, и их возникновение выше в сельских районах и в странах, нищета которых широко распространена. Такие аварии, способные повесять ряд потерь, могут приводить к последствиям на органическом и социально-экономическом уровне, поскольку они оправдывают необходимость инвестиций в профилактические методы и серу для лечения таких случаев (SALOMÃO et al., 2018). Рассматриваются как клиническая чрезвычайная ситуация (т.е. в которой необходимо немедленное внимание к пациенту), они вызваны рядом ядовитых животных, будучи скорпионами, пауками и змеями. В 2013 году в Бразилии было зарегистрировано 158002

$\mathrm{RC}: 67473$

Доступно в:

https://www.nucleodoconhecimento.com.br/здравоохранение/количество- 
случая несчастных случаев с ядовитыми анимами, большинство (около $78 \%$ от общего числа) было вызвано змеями (SILVA et al., 2015). Несчастные случаи на производстве, связанные с причинами, основанными на ядовитых животных, не регистрируются оптимально и занижены. Вместе с тем число таких случаев увеличивается с учетом периода, который охватывает период с 2007 по 2017 год (BRASIL, 2019 год).

По количеству несчастных случаев, вызванных ядовитыми животными, чемпионом по количеству несчастных случаев является юго-восточный регион, основными причинами которых являются змеи и скорпионы. Среди них, как было показано, скорпионы являются основными причинами этой проблемы, поскольку они находят в городских районах хорошую адаптацию к окружающей среде, фрактор, который обеспечивает воспроизводство и последующее распространение этого животного в регионе. Значительная часть несчастных случаев со скорпионом имеет легкие последствия для организма человека и не требует применения серотерапии. Однако в других случаях могут иметь место значительные различия в последствиях от человека к человеку, при этом смерть является возможным результатом, если не существует надлежащего лечения. Кроме того, могут быть сиквелы таких аварий, с тем чтобы ухудшить повседневную динамику человека, что затрудняет даже работу (LIMA et al., 2020).

Значительная часть случаев несчастных случаев с ядовитыми животными (большинство из них) происходят с мужчинами, и это утверждение является действительным для подавляющего большинства ядовитых животных. В частности, среди несчастных случаев наиболее распространен эпидемиологический профиль сельских рабочих, возраст которых составляет от 15 до 49 лет (BRASIL, 2019). Мальчики, как правило, страдают больше несчастных случаев от ядовитых животных в связи с такими аспектами, как

RC: 67473

Доступно в:

https://www.nucleodoconhecimento.com.br/здравоохранение/количество- 
отсутствие надзора в наружной рекреационных мероприятий, в дополнение к другим социально-культурным вопросам (NEIVA et al., 2019). Возрастная группа, в которой зарегистрировано наибольшее число случаев заболевания, составляет от 20 до 39 лет, и в период с 2009 по 2013 год число случаев заболевания в этой группе (SILVA et al., 2015a). С учетом собранных данных наибольшее число лиц, пострадавших в результате несчастных случаев с ядовитыми животными, имеет коричневую этническую принадлежность, за которой следуют белые и чернокожие.

Среди несчастных случаев и смертей, вызванных ядовитыми животными, скорпионы являются наиболее ответственными в течение изучаемого периода. В юго-восточном регионе (регионе, где преобладают несчастные случаи с ядовитыми животными), причины смерти и несчастных случаев среди скорпионов являются причиной наибольшего среднего числа смертей и несчастных случаев в этой категории (LIMA et al., 2020). Среди несчастных случаев на производстве, которые происходят по причинам скорпиона, наиболее пострадавшими частями тела являются руки, ноги и руки, с учетом периода с 2007 по 2017 год (BRASIL, 2019).

Ботропические аварии соответствуют наиболее распространенному в стране окислему, что составляет около 90\% от общего числа. Яд имеет ряд действий на органическом уровне в человеке, будучи в состоянии вызвать протеолитические, коагулянтные и геморрагические эфффекты. Кроме того, боль, отек, кровоподтеки и кровотечения в области укуса являются общими. Там также может быть появление волдырей и инфаркт ганглия групп (некроз региона может произойти, но не всегда присутствует). У беременных женщин, помимо этих проявлений, существует риск кровоизлияния в маточные заболевания, характеризующий случай большей тяжести (BRASIL, 2001).

$\mathrm{RC}: 67473$

Доступно в:

https://www.nucleodoconhecimento.com.br/здравоохранение/количество- 
Согласно представленным данным, среди лиц, пострадавших в результате несчастного случая, вызванного ядовитыми животными, большинство посещают медицинские службы в течение 3 часов после аварии. Время между укусом и уходом должно быть как можно меньше, и по данным, связанным с состоянием Rio Grande do Sul, по мере увеличения времени ухода увеличивается вероятность негативных последствий для человека, таких как уменьшение числа вылеченных пациентов и повышенная летальность. Хотя наибольшее число случаев смерти происходит среди мужчин, женщины имеют более высокий уровень летальности. В случае пожилых пациентов в возрасте 80 лет и старше наблюдался более высокий уровень летальности по сравнению с другими возрастными группами (DORNELES, 2009).

Несчастные случаи с ядовитыми животными, в их наибольшем количестве, не представляли собой классификацию, основанную на состоянии тяжести, то есть большинство из них были классифицированы как мягкий класс. Самый высокий уровень тяжести и летальности обычно наблюдается у детей старшего возраста и отдельных лиц (старше 80 лет) (DORNELES, 2009). В связи с несчастными случаями со скорпионами, большинство из них можно лечить в медицинском отделении, расположенном рядом с пациентом, не требуя серотерапии (LIMA et al., 2020).

Бразилия является одной из стран, которые производят наиболее антиядом сера во всем мире (около 400000 ампул). На национальном уровне лечение обеспечивается Единой системой здравоохранения, Бразилия является страной, свободное распространение антиофильной сыворотки делается более всеобъемлющим и с большей легкостью, так как она доступна для всех раненых. Сумма производится на национальном уровне является правильным, так что он может служить 100\% бразильских лиц. Однако по-прежнему существуют сложности, которые должны быть решены в отношении доступа ко

RC: 67473

Доступно в:

https://www.nucleodoconhecimento.com.br/здравоохранение/количество- 
всем регионам в полном роде, при этом коренные районы и местные отдаленные районы имеют более низкую доступность сыворотки (CUNHA, 2017).

\section{ЗАКЛЮЧЕНИЕ}

Рассматривается в качестве забытых причин заболеваний, несчастных случаев, вызванных ядовитыми животными, требующих более пристального внимания со стороны общественного здравоохранения, и необходимо улучшить систему уведомления о случаях заболевания и более широкую доступность информации по этому вопросу для населения в целом. Пауки, скорпионы и змеи являются основными причинами этих несчастных случаев.

Наиболее частым эпидемиологическим профрилем в одиозных авариях являются мужчины, сельские рабочие в возрасте от 15 до 49 лет. Среди детей больше всего страдают мальчики, и одной из основных причин этой проблемы является отсутствие надзора в повседневной деятельности.

Большинство несчастных случаев скорпиона создают незначительные последствия для человеческого организма и не подразумевают необходимость серотерапии. В других случаях, однако, могут быть значительные различия в последствиях от пациента к пациенту, и если нет адекватного лечения, пациент может быть насмерть.

Большинство случаев, как правило, посещают медицинские службы в течение 3 часов после аварии. Время между аварией и уходом должно быть как можно меньше, и по мере увеличения времени ухода вероятность негативных последствий для человека увеличивается пропорционально, со снижением уровня излечения и увеличением летальности.

RC: 67473

Доступно в:

https://www.nucleodoconhecimento.com.br/здравоохранение/количество- 
Большинство пациентов, которые испытывают аварии скорпиона не требуют серотерапии, и они могут прибегнуть к надлежащему лечению в медицинских отделениях, которые расположены в непосредственной близости от места, где произошла авария, так что движение быстрее и последующие темпы улучшения выше.

Производство сыворотки для лечения несчастных случаев с одидизами в Бразилии усиливается, и объем производимой продукции способен покрыть общее число случаев заболевания в стране. Вместе с тем существует проблема, связанная с распространением этой сыворотки, поскольку районы коренного населения и районы отдаленных населенных пунктов не имеют достаточной доступности, что позволяет иметь негативные последствия для отдельных лиц, что повышает вероятность смерти от такого рода несчастных случаев.

\section{ссылки}

BRASIL, Fundação Nacional de Saúde. Manual de Diagnóstico e tratamento de acidentes por animais peçonhentos, $2^{\underline{a}}$ ed., Brasília, 2001.

BRASIL, Portal da saúde. Série Histórica de Casos - Acidente Por Animais Peçonhentos. 2017. Acessado em 26 de setembro de 2017<http://portalarquivos.saude.gov.br/images/pdf/2017/abril/28/1-

SerieHistorica_1986-2016.pdf>

BRASIL. Secretaria de Vigilância em Saúde. Ministério da Saúde. Boletim Epidemiológico 11: Acidentes de trabalho por animais peçonhentos entre trabalhadores do campo, floresta, águas, Brasil 2007 a 2017, v. 50, 2019.

RC: 67473

Доступно в:

https://www.nucleodoconhecimento.com.br/здравоохранение/количество- 
BREDT C. S, LITCHTENEKER K. Avaliação Clínica e Epidemiológica dos acidentes com animais peçonhentos atendidos no Hospital Universitário do Oeste do Paraná 2008- 2012. Rev. Med. Res., Curitiba, v.16, n.1, p. 11-17, jan./mar. 2014.

CARMO É. A, NERY A. A, JESUS C. S, CASOTTI C. A. Internaçoes hospitalares por causas externas envolvendo contato com animais em um hospital geral do interior da Bahia, 2009-2011. Epidemiol. Serv. Saude, Brasília, p.105-114, jan./mar. 2016.

CUNHA, L. E. R. Soros antiofídicos: história, evolução e futuro. Journal Health NPEPS, v. 2, supl. 1, p. 1-4, 2017.

DORNELES, A. L. Frequência de acidentes por animais peçonhentos ocorridos no Rio Grande do Sul, 2001 - 2006. Trabalho de Conclusão de curso, Especialização em Saúde Pública, Proto Alegre, RS. 2009.

LIMA E. C. F, FARIA M. D, MORAIS R. M. R. B, OLIVEIRA L. M. S. R, LIMA E. H. F, COSTA C. S. Interações entre meio ambiente, atendimentos antirrábicos e acidentes por animais peçonhentos no município de Petrolina(PE). Saúde Meio Ambient, v.6, n.1, p.54-70, jan./jun. 2017.

LIMA, C. A.; LEAL, A. L. R.; MANGUEIRA, S. A. L.; COSTA, S. M.; SANTOS, D. F. Vigilância em saúde: acidentes e óbitos provocados por animais peçonhentos na região sudeste Brasil, 2005-2015. Revista de Pesquisa: Cuidado é Fundamental Online, v. 12, p. 20-28, 2020.

LOPES A. B, OLIVEIRA A. A, DIAS F. C. F, SANTANA V. M. X, OLIVEIRA V. S, LIBERATO A. A, CALADO E. J. R, LOBO P. H. P, GUSMÃO K. E, GUEDES V. R. Perfil Epidemiológico dos Acidentes por Animais Peçonhentos na Região Norte Entre os Anos entre 2012 e 2015: Uma Revisão. Revista de Patologia do Tocantins, v.4, n.2, p.36-40, 2017.

RC: 67473

Доступно в:

https://www.nucleodoconhecimento.com.br/здравоохранение/количество- 
NEIVA, C.A.C et al. Caracterização epidemiológica das intoxicações exógenas por substâncias nocivas e acidentes por animais peçonhentos em crianças no Estado do Amapá. Revista Científica Multidisciplinar Núcleo do Conhecimento, v. 01, p. 41-66, 2019. https://www.nucleodoconhecimento.com.br/saude/caracterizacaoepidemiologica

SALOMÃO, M. G.; LUNA, K. P. O.; MACHADO, C. Epidemiologia dos acidentes por animais peçonhentos e a distribuição de soros: estado de arte e a situação mundial. Rev. Salud Pública, v. 20, n. 4, p. 523-529, 2018.

SANTANA V. T. P, SUCHARA E. A. Epidemiologia dos acidentes com animais peçonhentos registrados em Nova Xavantina - MT. Revista de Epidemiologia e Controle de Infecção, v.5, n.3, p.141-146, 2015.

SILVA C. T., PARDAL P. P. Atividades Lúdicas Na Prevenção De Acidentes Por Animais Peçonhentos Em Estudantes Da Rede Pública Da Região Metropolitana De Belém. Revista Universo \& Extensão, v.3, n.3, 2015.

SILVA, A. M.; BERNARDE, P. S.; ABREU, L. C. Acidentes com animais peçonhentos no Brasil por sexo e idade. Journal of Human Growth and Development, v. 25, n. 1, p. 54-62, 2015a.

SILVA J. H, GIANSANTE S, SILVA R. C. R, SILVA G. B, SILVA L. B, PINHEIRO L. C. B. Perfil Epidemiológico dos Acidentes com Animais Peçonhentos em Tangará da Serra-Mt, Brasil (2007-2016). Journal Health NPEPS, p.5-15, 2017.

SOUZA C. M. V, MACHADO C. Animais peçonhentos de importância médica no município do rio de janeiro. Journal Health NPEPS, p.16-39 2017.

Представлено: Декабрь 2020 года.

$\mathrm{RC}: 67473$

Доступно в:

https://www.nucleodoconhecimento.com.br/здравоохранение/количество- 
Утверждено: Декабрь 2020 года.

RC: 67473

Доступно в:

https://www.nucleodoconhecimento.com.br/здравоохранение/количество-

несчастных 